\title{
Geodetic work during implementation of environmental protection measures for the remediation of oil-contaminated lands
}

\author{
Nina Rogova ${ }^{1, *}$ \\ ${ }^{1}$ Moscow State University of Civil Engineering, 26 Yaroslavskoye Shosse, Moscow, 109377, Russia
}

\begin{abstract}
At the present level, the production, transportation and primary processing of oil products is associated with the problem of environmental pollution. The ingress of oil products into the natural environment leads to negative consequences and requires the enterprise to incur additional costs to eliminate the emergency situation and to take environmental protection measures to restore oil-contaminated territories. To restore contaminated territories on the basis of field surveys, which are based on geodetic work, remediation projects are developed. Remediation is carried out on the basis of a project, the reliability of which is taken into account during field geodetic work on determining the site area. In the course of the calculations, it was found that the use of tacheometric survey can significantly increase the cost of field work. In most cases, to ensure the development of a remediation project, it is enough to use domestic GPS receivers. The use of this class of devices will reduce both the timing of field work and their cost. It should be borne in mind that the accuracy of domestic GPS receivers allows using them in determining sites with an area of more than 0.5 ha.
\end{abstract}

\section{Introduction}

In accordance with the legislation of the Russian Federation, each enterprise that has allowed pollution of the environment as a result of its activities, including with oil products, is required to carry out its restoration [1].

Most oil and gas companies inevitably have to deal with the problem of environmental pollution due to accidental oil spills (Fig. 1,2) during production, transportation or its primary processing. For an enterprise, the negative consequences of the release of petroleum products into the environment are the costs of the liquidation of the accident, penalties, remediation of contaminated lands, and reputation risks.

In practice, the restoration of land contaminated with oil products is solved through remediation. Land remediation is a set of measures aimed at restoring the former fertile qualities of the land, its biological and economic value, as well as improving environmental conditions.

\footnotetext{
* Corresponding author: doptaganka@yandex.ru
} 
In case of an accident and the ingress of oil products into the environment, the enterprise is obliged, according to the instructions for land restoration [2], to immediately take a number of measures: eliminate the accident, localize the spread of oil on the ground or water surface, collect as much spilled oil products as possible. In the future, to eliminate the negative consequences, a field survey of the site is carried out, on the basis of which a project for its remediation is being developed. The main type of field survey is geodetic work. The timing and cost of remediation work depend on the reliability and quality of it.

\section{Materials and methods}

Soil pollution with oil products sharply worsens their physicochemical and water-air properties and, in most cases, leads to the death of natural vegetation and tree crops. When it gets into swamps, rivers, and lakes, it makes them unsuitable for aquatic life. The process of land remediation is very laborious and expensive, and should be carried out on the basis of a project for the restoration of oil-contaminated territories [3]. The technology of remediation of oil-contaminated lands is carried out in two stages: technical and biological. The timing of the stages of remediation depends on the transport accessibility of the site, its area, and its water cut.

Figures 1 and 2 show typical sites contaminated with oil products. Moreover, in Figure 2 , oil products enter the aquatic environment. These two figures clearly show that there should be a different approach to them during their remediation.

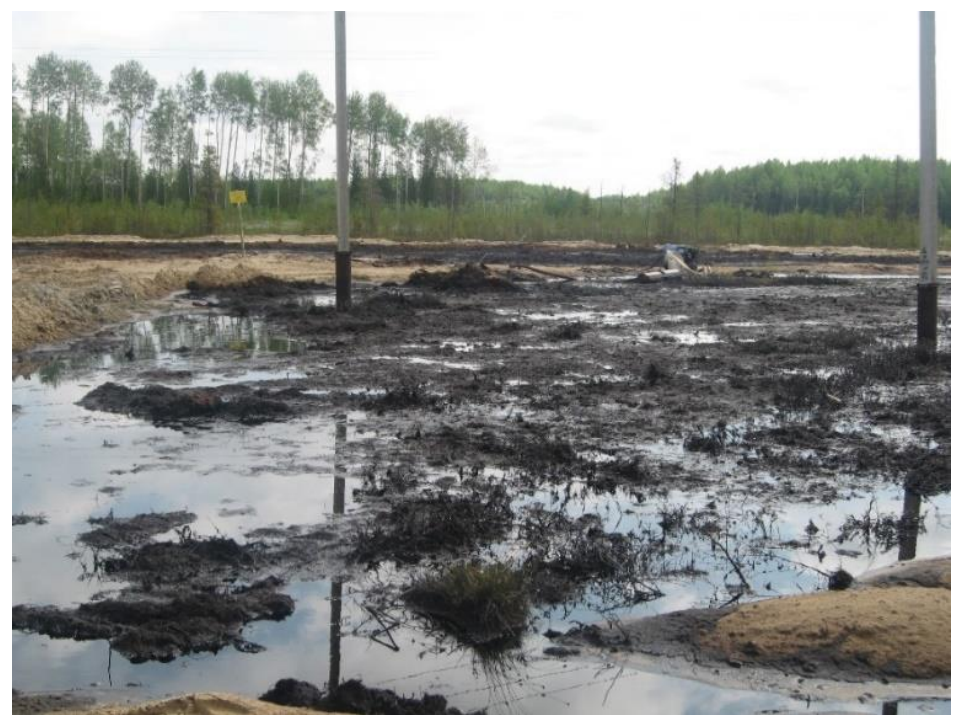

Fig. 1. Oil-contaminated area, which is subject to remediation (photo from the author's personal archive).

When developing a remediation project, the main type of work is field survey to determine the area and volume of contaminated land to be removed and cleaned. For this, a complex of geodetic works is carried out, which is fundamental, since the accuracy of these definitions determines the reliability of the indicators built into the project and, ultimately, the cost indicators of the restoration of a particular area, which is of great importance for the oil producing enterprise and the contractor performing the restoration. At the stage of developing a remediation project, the determination of the area of an oil-contaminated site is carried out analytically. 


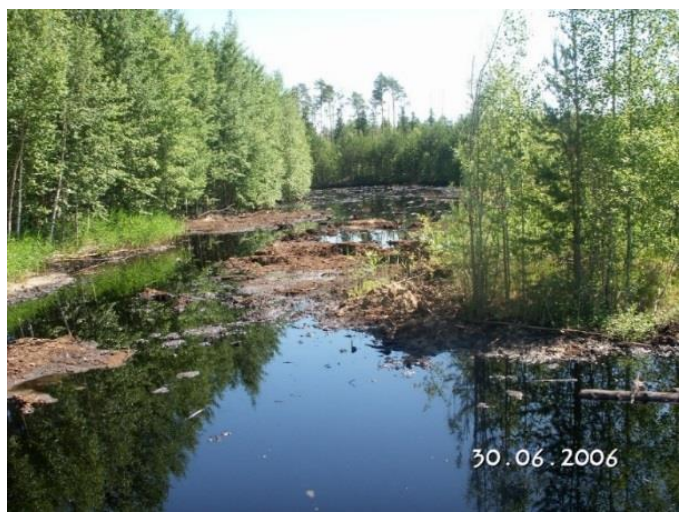

Fig. 2. Oil-contaminated area with oil entering the aquatic environment (photo from the author's personal archive).

It is based on the calculation of the area according to the results of measuring lines and angles on the ground using the formulas of geometry and trigonometry, as well as the coordinates of the vertices of the turning points of the border of the land plot. In practice, using traditional methods for determining the area, the method of determining the area of a closed polygon by the coordinates of its vertices was widely used, while the accuracy of the definitions corresponded to the requirements of the instructions for topographic surveys [4]. For this, in the field, a theodolite traverse was laid along the vertices of the oil-contaminated area (see Fig. 3).

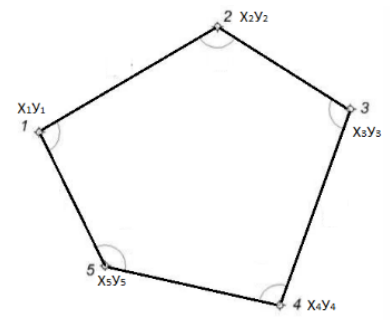

Fig. 3. The closed theodolite traverse, the vertices of which coincide with the boundaries of the land plot.

In this case, the determination of the area is carried out according to well-known formulas:

$$
\begin{aligned}
& S=\frac{1}{2} \sum_{1}^{n} X_{n}\left(Y_{n+1}-Y_{n-1}\right) \\
& S=\frac{1}{2} \sum_{1}^{n} Y_{n}\left(X_{n-1}-X_{n+1}\right)
\end{aligned}
$$

Where:

$\mathrm{X}, \mathrm{Y}$ - the coordinates of the vertices of the main theodolite traverse;

$\mathrm{n}-$ the vertices of the traverse;

$(n+1)$ - the number of the subsequent vertex;

$(n-1)-$ the number of the previous vertex.

The area is calculated by both formulas, which was the control of calculating the area of the site. The implementation of this method with the laying of theodolite and tacheometric 
traverses is complicated by the physical and geographical conditions of the region. In summer, the inaccessibility of most of the territory is caused by the continuous swampiness of the area, in winter - due to the snow cover hiding the borders of the oil-contaminated area. When oil products get into water bodies, projects should additionally take into account scope of work to collect oil products from the water surface, clean the coastline and collect oilcontaminated bottom sediments [7-11].

Figure 4 shows an example of surveying an oil-contaminated area by a domestic GPS receiver with superimposing on a topographic plan on a scale of 1: 2000. The topographic plan shows the oil-contaminated area, the access road made to eliminate the accident on the pipeline, and the creek along which the spread of oil pollution occurred. During a field survey, in addition to surveying, all the necessary parameters characterizing pollution are recorded: the type of vegetation, soil characteristics, the depth of penetration of oil in it, etc.

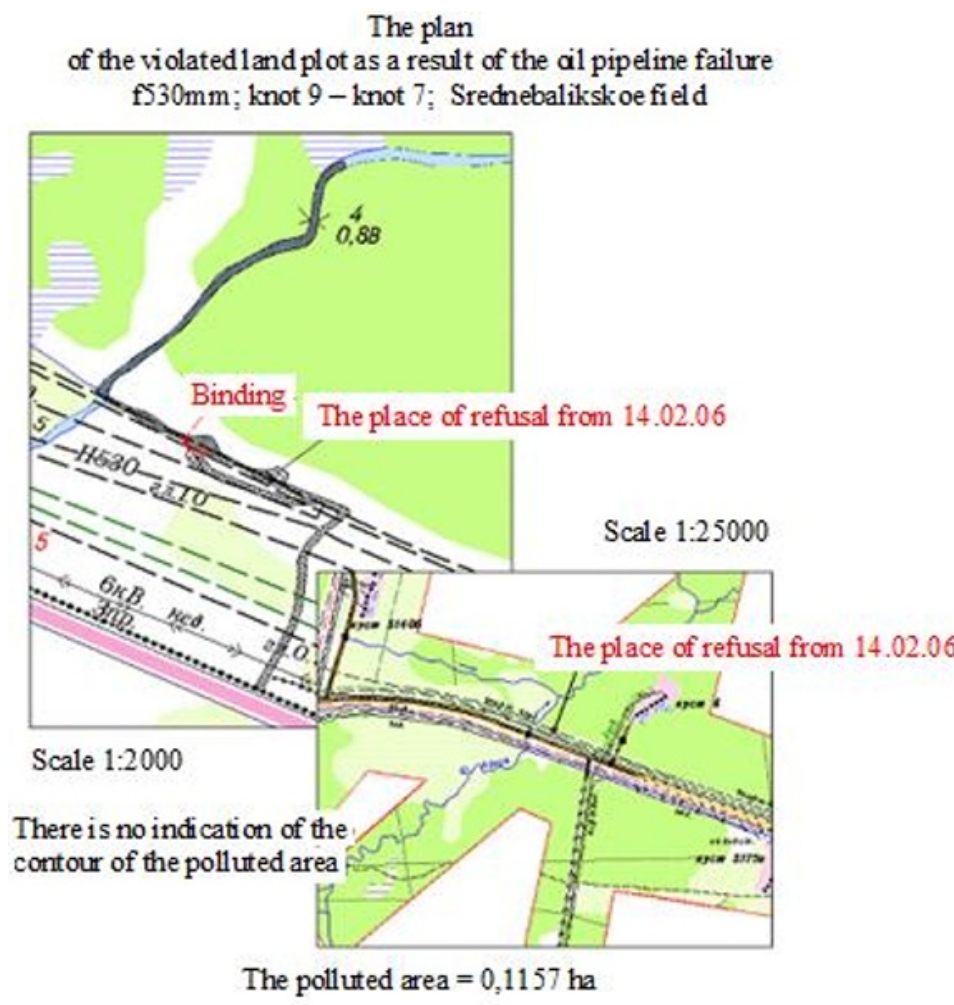

The ar ea of the entrance $=0,0794 \mathrm{ha}$

\section{Pefform ed by. Specialist KrugleyE.V. $\quad 15.07 .2012$}

Fig. 4. Topographic plan on a scale of 1: 2000 of oil-contaminated land as a result of a failure of the pipeline and a fragment of a survey map on a scale of 1:25000.

Of the many methods for determining the coordinates of the turning points of the land plot, an analytical method based on the use of domestic GPS receivers is currently used in practice [5]. The maximum possible accuracy of determining the coordinates in the horizontal plane using these receivers is 2-3 meters (in case of good visibility of the sky). In most cases, surveys of oil-contaminated sites in the field are performed by GARMIN GPS navigators. The data obtained using a GPS navigator can easily be transferred to MapInfo GIS (version no lower than V11.0 or V11.5) [6] with a preloaded map of the region in which waypoints 
and tracks were recorded. When working with Garmin GPS navigators and MapInfo GIS, one important condition must be observed. The map to which you plan to import data from the navigator must have a WGS84 coordinate system (in this coordinate system, data from satellites is received, and in this case, data and map synchronization is necessary).

It is known that the mean square error of determining the area of a land plot having a rectangular shape is calculated by the formula:

$$
m_{s}=m_{t} \sqrt{S} \sqrt{\frac{1+K^{2}}{2 K}}
$$

Where:

$S$ - land plot area,

$K$ - coefficient of elongation of the plot $K=\frac{d}{l}$ ( $d$ - length of the plot, $l$ - width of the plot),

$m_{t^{-}}$mean square error of the turning point of the plot

$$
m_{t}=\sqrt{m_{x}^{2}+m_{y}^{2}}
$$

Where $m_{x}, m_{y}$ - mean square errors of determining the coordinates of the vertices of the land plot.

If the plot has a square shape, the mean square error of determining the plot area is determined by the formula:

$$
m_{s}=m_{t} a
$$

Where: a - side length of a square.

With the square shape of the site $(K=4)$, we have:

$$
m_{s}=1,46 m_{t} \sqrt{S}
$$

To determine the mean square error of determining the area of the plot having an arbitrary shape, use the well-known formula:

$$
m_{s}=m_{t} \sqrt{\frac{1}{8} \sum\left\{\left(X_{k+1}-X_{k-1}\right)^{2}+\left(Y_{k+1}-Y_{k-1}\right)^{2}\right\}}
$$

Where: $m_{t}$ - mean square error in the position of the turning point of the plot; $X_{k+1}, X_{k-1}$ - coordinates of the subsequent and previous turning points.

\section{Results}

According to existing standards [2, 3], the error in determining the area of an oilcontaminated site should not exceed 5\% of its area. Figure 5 shows the relationship between the errors in determining the area of the plot and the coordinates of its vertices. 


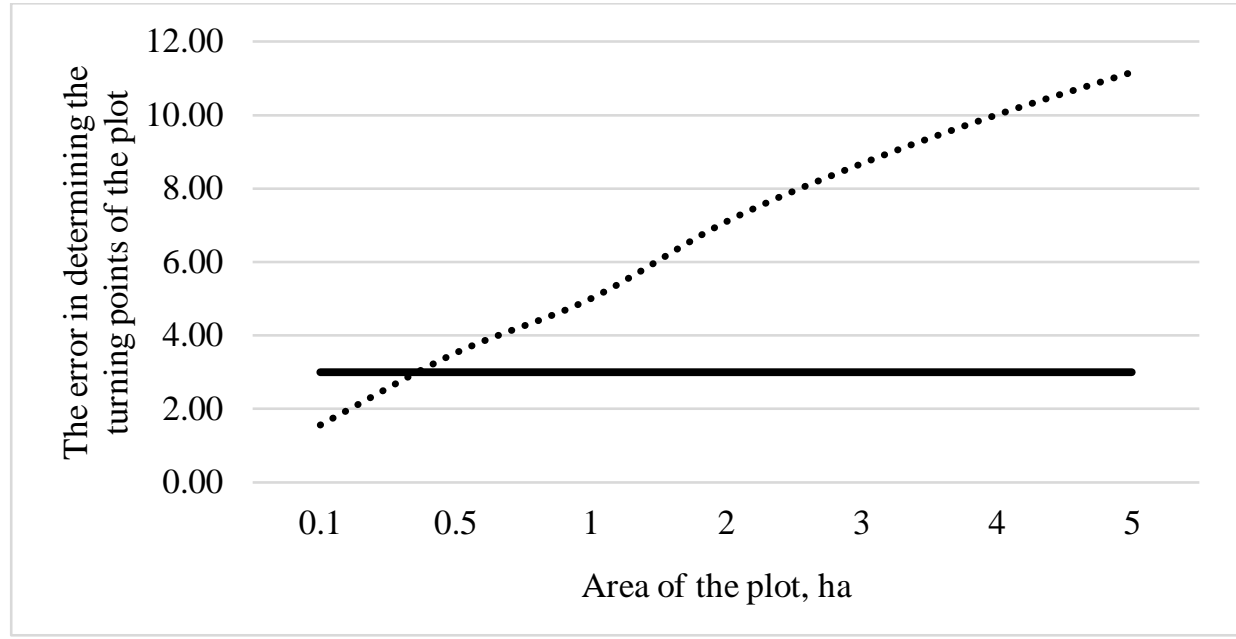

..... - the error in determining the area, - - the error of GPS

Fig. 5. The graph of the dependence of the error in determining the area of the plot on the error in determining the coordinates of its vertices by domestic GPS receivers.

An analysis of the dependence of the error in determining the area of the plot on the error in determining the coordinates of its vertices shows that an analytical method based on the use of domestic GPS receivers can be used to determine the area of plots over 0.5 ha. To determine the areas of small (less than $0.5 \mathrm{ha}$ ) areas of contaminated land, it is necessary to carry out field geodetic measurements in the form of tacheometric or theodolite traverses [3]. Table 1 shows the data characterizing the accuracy of determining the position of the turning points of the plot, depending on the scale of survey.

Table 1. The data characterizing the accuracy of determining the position of the turning points of the plot, depending on the scale of survey.

\begin{tabular}{|c|c|}
\hline Scale of survey & $\begin{array}{c}\text { The error in determining the turning points of the plot, } \\
\mathbf{m}^{\mathbf{2}}\end{array}$ \\
\hline $1: 500$ & 0.35 \\
\hline $1: 1000$ & 0.7 \\
\hline $1: 2000$ & 1.4 \\
\hline $1: 5000$ & 3.5 \\
\hline
\end{tabular}

The graph in figure 6 clearly shows what error in determining the coordinates of the turning points of the plot must be taken into account so that the error in determining the area does not exceed $5 \%$ of the area of the plot. The figure shows that there is no need to determine the area of contaminated sites with an accuracy of topographic surveys of scales 1:500 and 1:1000, since this can lead to an unreasonable increase in the cost of field geodetic work. 


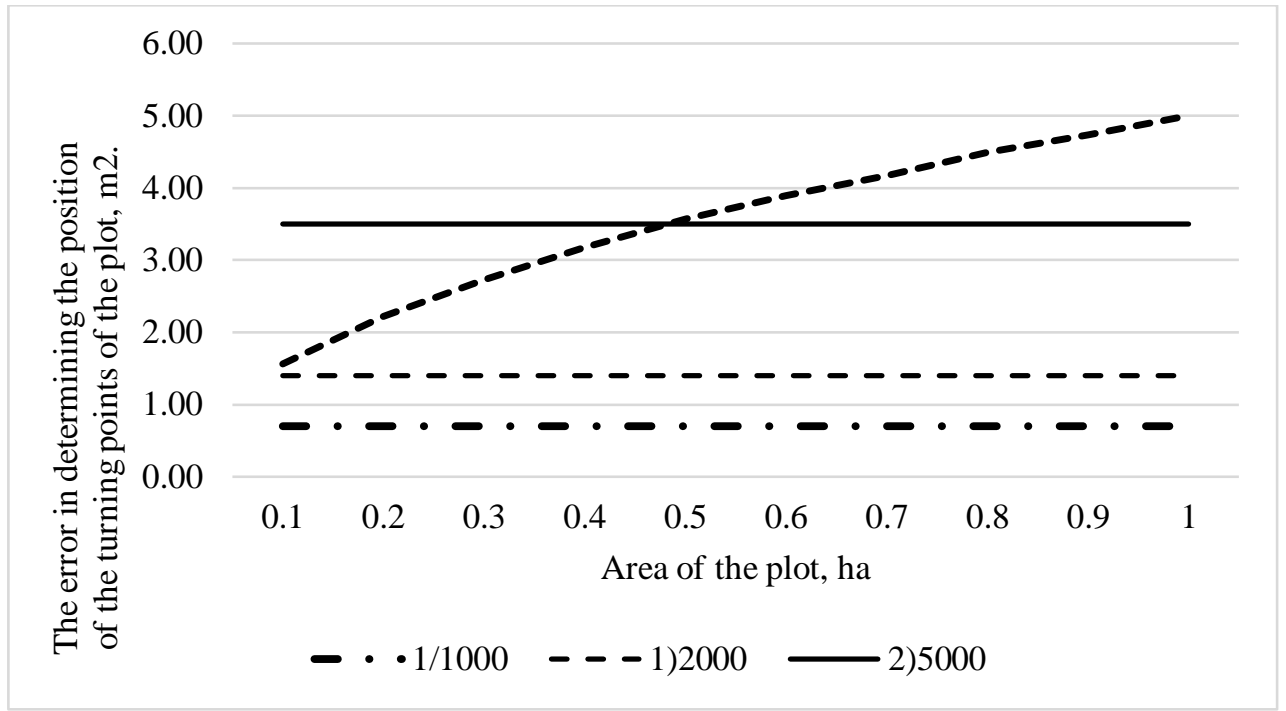

Fig. 6. The graph of the dependence of the error in determining the area of the plot on the error in determining the coordinates of its vertices by field geodetic measurements.

The data presented on the graph clearly show that with a plot area of more than 0.1 hectares, one should be guided by the accuracy shown for topographic plans on a scale of $1: 2000$. For plots whose area is more than 0.5 hectares, one should be guided by the accuracy of creating plans on a scale of 1:5000. If we take into account the data shown in Fig. 6, then we can talk about the permissibility of using domestic GPS-receivers to determine the area of oil-contaminated plots whose area is more than 0.5 hectares.

\section{Discussion}

An error in determining the area of a contaminated site will inevitably lead to an error in the estimated cost of remediation work. Knowing the area of the oil-contaminated site $S$, it is possible to determine the cost of remediation of this site using the formula:

$$
C=S * D
$$

Where: $D$ - tariff per unit area.

The mean square error of the cost determination is expressed by the formula $m_{c}=D m_{s}$, from which its direct dependence on the accuracy of determining the area of the site is obvious.

The value of $D$ is determined by other factors and its discussion is beyond the scope of this paper. Nevertheless, an understanding of this problem will allow specialists of both the customer and the contractor to minimize the risks of controversial and conflict situations.

\section{Conclusion}

The data presented in the paper on the application of various methods for determining the area of oil-contaminated sites were used in the development of a standard project for the remediation of oil-contaminated lands of Yuganskneftegaz OJSC and were recommended for use in subsequent remediation projects in the territory of Yuganskneftegaz OJSC. 


\section{References}

1. Russian State Standard GOST 17.5.3.04-83

2. Instructions for the restoration of lands disturbed and contaminated during emergency and capital repair of oil pipelines dated 6.02.1997 No. RD 39-00147105-006-97

3. A typical project for the remediation of oil-contaminated lands of Yuganskneftegas OJSC (2018)

4. K. Kornienko, S. Bessonenko, I. Tanaino, Advances in Intelligent Systems and Computing 1115, 655-662 (2020). DOI: 10.1007/978-3-030-37916-2_63

5. Garmin GPSMAP 60CSx user manual (2014)

6. Mapinfo Professional version 12.5 user manual (2014)

7. I.Yu. Grigoryeva, Oil pollution of soils: engineering-geological and environmentalgeological aspects. Saarbrucken (LAP LAMBERT Academic Publishing GmbH \& Co. KG, Germany, 2010)

8. I.Yu. Grigoryeva, D.Yu. Baranov, A.M. Abyzova, Engineering Surveys 13, 48-57 (2015)

9. I.Yu. Grigoryeva, A.N. Shestakova, Engineering geology 1, 30-33 (2009)

10. A.V. Saromotin, Materials of the district meeting (Khanty-Mansiysk, 1997)

11. L.P. Kapelkina, L.A. Malyshkina, Scientific journal "Oil Industry” (2015) ISSN: 00282448 